tion. Unexpected in vivo performance of a mechanical heart valve should be elucidated thoroughly and careful follow-up of affected patients is warranted.

\section{References}

1. Eichinger WB, Wagner IM, Bleiziffer S, von Canal F, Günzinger R, Ruzicka DJ, et al. Occasional single beat regurgitation observed with the Medtronic Advantage bileaflet heart valve. Ann Thorac Surg. 2006; 82:537-41.
2. Lindblum D, Rodriguez L, Björk VO. Mechanical failure of the BjörkShiley valve: updated follow-up and considerations on prophylactic replacement. J Thorac Cardiovasc Surg. 1989;97:95-7.

3. Bottio T, Casarotto D, Thiene G, Caprili L, Angelini A, Gerosa G. Leaflet escape in a new bileaflet mechanical valve: TRI Technologies. Circulation. 2003;107:2303-6.

4. Mosterd A, Shahin GMM, van Boven WJ, Jaarsma W, Graafland AD, van Swieten HA. Leaflet fracture of a St Jude mechanical bileaflet valve. Circulation. 2005;111:e280-1.

5. Tatou E, Selah M, Eicher JC, Brenot R, David M. Fracture-embolization of Duromedics valve prosthesis and microscopic uncommon lesions. Ann Thorac Surg. 2001;71:1366-9.

\title{
Cardiac papillary muscle hemangioma
}

\author{
Andrew E. Newcomb, MBBS, FRACS, ${ }^{\text {a }}$ Stefano Pelenghi, MD, ${ }^{\text {a }}$ Jacek Karski, MD, ${ }^{\text {b }}$ Jagdish Butany, MBBS, MS, FRCPC, \\ and Tirone E. David, MD, FRCS(C), ${ }^{a}$ Toronto, Ontario, Canada
}

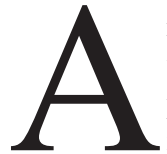

rare case of left ventricular hemangioma in combination with mitral valve prolapse is reported. The neoplasm was seen close to the tip of the posterior papillary muscle. The definitive diagnosis was made at the time of postresection pathologic examination. A literature review confirms the need for resection, if possible.

\section{Clinical Summary}

An echocardiogram on a 40-year-old man being observed for mitral valve regurgitation revealed a $1.4-\mathrm{cm}$ diameter mass on the posterior papillary muscle. The mass had not been noted on previous examination 3 years prior. History and physical examination were unremarkable. An angiogram confirmed $2+$ mitral regurgitation. Results of all other investigations were within normal limits. A clinical diagnosis of myxoma was made, and to avoid any chance of tumor embolization, urgent surgery was scheduled.

An intraoperative transesophageal echocardiogram (TEE) confirmed A2 prolapse and a heterogeneous $1.7-\mathrm{cm}$ diameter mass in the left ventricle attached to chordae tendineae adjacent to the posterolateral papillary muscle (Figure 1). Using cardiopulmonary bypass and hypothermic arrest, we opened the left atrium wide through the

From the Division of Cardiovascular Surgery, ${ }^{\mathrm{a}}$ and Departments of Anesthesia, ${ }^{\mathrm{b}}$ and Pathology, ${ }^{\mathrm{c}}$ Toronto General Hospital, Toronto, Ontario, Canada.

Tirone E. David, MD, FRCS(C), reports consulting and lecture fees from Medtronic.

Received for publication June 3, 2007; accepted for publication June 21, 2007.

Address for reprints: Andrew Newcomb, MBBS, FRACS, Division Cardiovascular Surgery, Toronto General Hospital, 200 Elizabeth St, 4N459, Toronto, Ontario M5G 2C4, Canada (E-mail: andrewenewcomb@gmail. com).

J Thorac Cardiovasc Surg 2007;134:1345-6

$0022-5223 / \$ 32.00$

Copyright $(2007$ by The American Association for Thoracic Surgery doi:10.1016/j.jtcvs.2007.06.032 interatrial groove. A spherical mass attached to the medial portion of the anterior trunk of the posterior papillary muscle, approximately 1 $\mathrm{cm}$ below the level where the chordae tendineae attach, was identified (Figure 2) and removed along with a 3- to 4-mm rim of papillary muscle around the base (Figure 2, inset). The remaining muscle looked viable and strong. The A2 prolapse was corrected with 6 polytetrafluoroethylene neochordae (Gore-Tex; registered trade mark of W. L. Gore \& Associates, Inc, Flagstaff, Ariz) between the posterior papillary muscle and the free margin of the leaflet. A posterior annuloplasty band with a Medtronic Simplici-T (Medtronic, Inc, Minneapolis, Minn) $64 \mathrm{~mm}$ in length was performed.

The postprocedure TEE showed normal valvular function. The postoperative course was uneventful and the patient was discharged home 5 days after the operation. Follow-up review at 2 months showed no mitral regurgitation or tumor recurrence.

Histopathologic examination revealed a $1.5-\mathrm{cm}$ diameter mass comprising vascular channels (CD31 positive cells on immunohistochemical staining [antibodies from Dako Diagnostics, Mississauga, Ontario, Canada]) with the histologic appearance of hemangioma. There were small (capillary) and large (cavernous) vascular structures of varying sizes with variable amounts of endothelial cells and smooth muscle cells separated by a loose, partly myxoid matrix. The smooth muscle actin stain was also positive in cells surrounding the vascular channels.

\section{Discussion}

Primary cardiac tumors are rare and most are benign. Hemangiomas account for $5 \%$ to $10 \%$ of these benign tumors. ${ }^{1}$ They may present at any age and there is a slight male preponderance. Hemangiomas may be found in any layer of the heart and in any chamber; however, there is a tendency for the right heart and left atrium to be more frequently involved. ${ }^{2}$

Microscopically, these are composed of vascular endothelial cells and may be classified into capillary, cavernous, venous, or racemose in nature. ${ }^{3}$ Most hemangiomas are small subendocardial bluish nodules and range in size from 2 to $3.5 \mathrm{~cm}$. They may be sessile or polypoid and are mostly solitary. ${ }^{2}$ These tumors are 


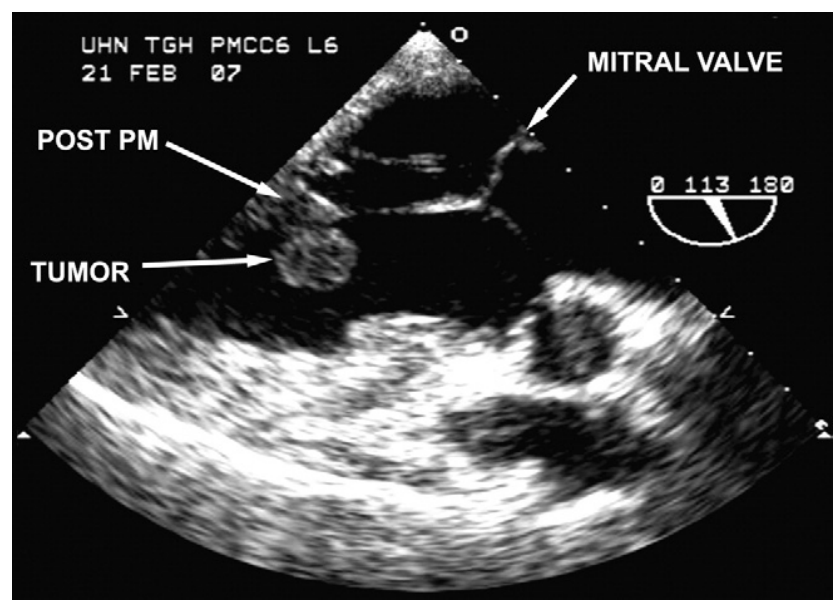

Figure 1. Intraoperative transgastric long-axis TEE image showing the mass and its relationship to the posterior papillary muscle (POST PM).

usually asymptomatic, but symptoms may reflect the anatomic location of the tumor. They have been reported to induce arrhythmias, coronary insufficiency, pericardial effusions, effort dyspnea, outflow tract obstruction, and congestive heart failure. ${ }^{3}$

In our patient, myxoma was suspected on the basis of TEE, and intraoperative assessment also led the surgical team to suspect myxoma. The definitive diagnosis was only completed with formal histologic evaluation. Echocardiographic scanning or cardiac catheterization will usually establish a diagnosis of cardiac tumor by showing an intracavity filling defect and a tumor blush, ${ }^{2,3}$ but more intensive diagnostic examinations are needed to correctly define the type of tumor. ${ }^{4}$

Surgical resection is desirable but may be impossible depending on the tumor's location. Because the diagnosis of these rare tumors is often made post mortem, the natural history is unknown, ${ }^{2,3}$ so a definitive management plan in the setting of an unresectable lesion cannot be recommended. Some reported cases

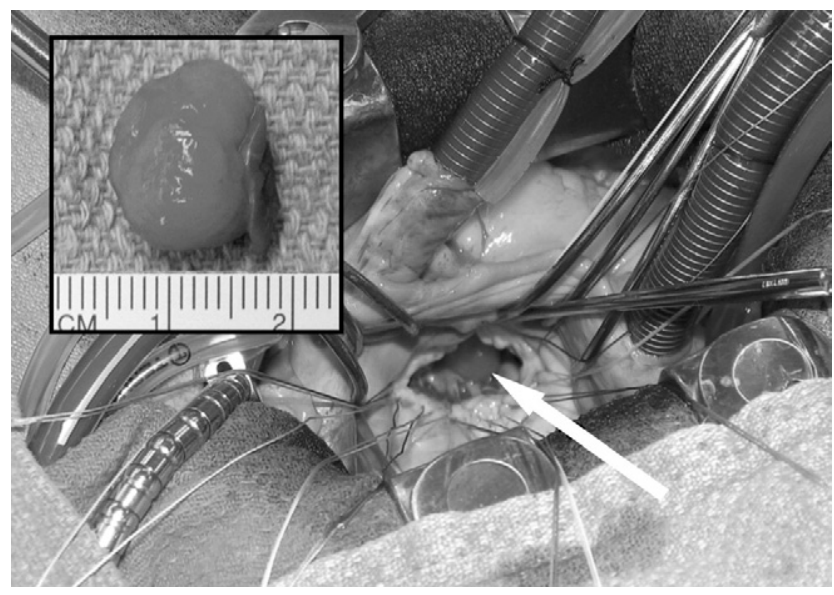

Figure 2. Clinical photograph of the mass confirming the position as seen through the mitral valve (white arrow). Inset, Resected specimen with attached papillary muscle.

of tumor debulking have produced long-term benefits, ${ }^{3,5}$ but there have also been reports of recurrence after complete extirpation. ${ }^{2}$

This case confirms that hemangioma is a rare asymptomatic tumor that may be identified with the increase in noninvasive cardiac investigations. It also reinforces the need for surgical intervention for risk reduction and definitive histologic diagnosis.

\section{References}

1. Burke A, Virmani R. Tumors of the heart and great vessels. In: Rosai J, Sobin LH, editors. Atlas of tumor pathology. 3rd series, fascicle 16 Washington, DC: Armed Forces Institute of Pathology; 1996. p. 80-6.

2. Chao JC, Reyes CV, Hwang MH. Cardiac hemangioma. South Med J. 1990;83:44-7.

3. Brizard C, Latremouille C, Jebara VA, Acar C, Fabiani JN, Deloche A, et al. Cardiac hemangiomas. Ann Thorac Surg. 1993;56:390-4.

4. Zeina AR, Zaid G, Sharif D, Rosenshein U, Barmeir E. Huge pericardial hemangioma imaging. Circulation. 2007:115:e315-7.

5. Grebenc ML, Rosado de Christenson ML, Burke AP, Green CE, Galvin JR. Primary cardiac and pericardial neoplasms: radiologic-pathologic correlation. Radiographics. 2000;20:1073-103. 